\title{
Establishing a metrological infrastructure and traceability of electrical power and energy in the R. Macedonia
}

\author{
Ljupco Arsov, Marija Cundeva-Blajer \\ Ss. Cyril and Methodius University, Faculty of Electrical Engineering and Information Technologies-Skopje, Ruger Boskovic b.b., POB 574, \\ 1000 Skopje, R. Macedonia
}

\begin{abstract}
In the paper the current state and the establishment of a metrological infrastructure and traceability of the measurements of electrical power and energy, i.e. the creation of conditions for unity of power and energy measurement results, international comparability of the results and measurements which insure fair trade and consumers' protection are elaborated. Beside the legal aspects, also other features are discussed, like the needs for calibration and verification in the field of electrical power and energy, participants in the chain of measurements and trade with electrical energy, the organization, the infrastructure, the methods and the systems of calibration and verification. An organization and certain documents which will contribute to the establishment of a system in accordance with the international standards and practice, as well as traceability and fair trade, are proposed.
\end{abstract}

\section{Section: TECHNICAL NOTE}

Keywords: metrological infrastructure; power and energy measurements; calibrations; standards

Citation: Ljupco Arsov, Marija Cundeva-Blajer, Establishing metrology infrastructure and traceability of electrical power and energy in R. Macedonia, Acta IMEKO, vol. 2, no. 2, article 15, December 2013, identifier: IMEKO-ACTA-02 (2013)-02-15

Editor: Paolo Carbone, University of Perugia

Received April 12 ${ }^{\text {nd }}, 2013$; In final form December $2^{\text {nd }}, 2013$; Published December 2013

Copyright: (C) 2013 IMEKO. This is an open-access article distributed under the terms of the Creative Commons Attribution 3.0 License, which permits unrestricted use, distribution, and reproduction in any medium, provided the original author and source are credited

Funding: This work was supported by Faculty of Electrical Engineering and Information Technologies-Skopje

Corresponding author: Marija Cundeva-Blajer, e-mail: mcundeva@feit.ukim.edu.mk

\section{INTRODUCTION}

After gaining the independence of the R. Macedonia, the process of creating a metrological system and an infrastructure necessary for the establishment of measurement standards and metrological traceability has begun. The development has started with the creation of own legislative, institutions, equipment and infrastructure for the application of legal and industrial metrology. For the measurement of electrical energy and power, in the frame of legal metrology, nothing was inherited from the former Yugoslav system. However, the significance of these measurements impose quick measures to be undertaken, because of the large needs and quantity, the large finances connected to the trade of electrical energy, the need of consumers' protection and insurance of conditions of fair trade. The adequacy of these solutions, the need of their upgrading and improvement, as well as the model which would create conditions for fair trade and electrical energy consumers' protection are further discussed.

\section{CURRENT STATE OF THE ART}

The field of measurements of electrical energy and power is legaly regulated by the Law on Metrology from 2002 [1]. Beside this Law a set of Rulebooks [2-4] are adopted. Currently, there is a process of a transposition of the EU documents in the field of metrology, which are connected to certain types of measuring instruments (sector directives), [5].

Through the Law on Metrology [1], as one of the basic objectives in the legal regulation of the measurements of electrical energy, the condition on insurance of fair trade is posed. This fair trade will be insured by exact measurements of the electrical energy, with legally aproved instruments in compliance to the Rulebook on Measuring Instruments [3], calibrated and verified, and with measurements traceable to the national standard.

The traceability requirement, defined in Article 3 of the Law on Metrology [1], although it is not explicitly stated, should insure measurement traceability to the national standard of the R. Macedonia, to national standards of other states and to international standards. 
By taking into account that the trade of electrical energy is not only internal, but in a large part international, it is necessary to insure traceability and comparability of the results not only on a national, but also on an international level. The same addresses also to the usage of electricity meters, which should comply with the specifications of the domestic regulation [3] as well as with the European regulation [5]. From the aspect of law regulation, this requirment is fulfilled through transposition of the EU directives and harmonization of the national laws and regulation with the EU directives in the field of metrology.

In respect to the compliance of the electricity meters to the requirements of the regulation, which is declared through posing of the „CE“ mark, and which presumes existence of a notified body which will participate in the procedure of approval and marking, it is unclear how the domestic producers could address this question, since the R. Macedonia is not a member of the EU.

According to the Law on Metrology [1], in order to insure the conditions for fair trade, the electricity meters should be verified, which is done by legal and physical entities selling electrical energy, and formally by the Bureau of Metrology of the R. Macedonia. If the requirements of the international standard for bodies performing inspection [6] and the international standard for testing and calibration laboratories [7] are taken into account, this solution, inherited from the former system, is in contradiction to the requirements of these standards in respect to the independence, impartiality, integrity and confidentiality of the bodies performing verification (control), e.g. calibration. This has become especially obvious after the process of privatization of the distribution of electrical energy in 2006. The control performed by the interested body is in conflict with the requirement for independent, impartial, and confidential control of the electrical energy measurements.

The market of electrical energy in the R. Macedonia is not well developed yet. Main participants in the trade of electrical energy are EVN-Macedonia, MEPSO, ELEM, licenced trade houses as well as the large industrial consumers (Mak-Steel Skopje, FENI Industry Kavadarci, Mital Steel-Skopje etc.), light industry and the households. The Bureau of Metrology of the R. Macedonia is in charge to insure the unity of the measurements of electrical energy, national standard of electrical energy, type approvals of the electricity meters produced according to the legal requirements, periodical verification/calibration, metrological surveilance of the electricity meters and measurement traceability to the national standard. The Bureau of Metrology of RM, by the help of the $\mathrm{EU}$, has formed and partially equipped its laboratories in the last years. However in the laboratory for electrical energy there is no electrical power standard, so the Bureau is not in a position to insure traceability of the electrical energy measurements i.e. is not in a position to calibrate standards and instruments for electrical power.

The legal requirement for verification of the electricity meters is realized through verification (calibration) of electricity meters in the EVN-Macedonia laboratory for verification of electricity meters, which has 6 verification systems EMH/MTE on disposal equipped with a power standard, accuracy class 0.05 . After the control/verification by the EVN-Macedonia, the Bureau of Metrology on the basis of the control results formally performs the verification and sealing. The Bureau of Metrology performs the metrological surveilance and verification through its Department for verification of electricity meters. However, the methods of surveillance of the verification (metrological control) according to the equipment for control, sampling frequency, number of samples and the application of proper statistical methods according to the standards (IEC 62058-11, [8], IEC 62058-21, [9], IEC 62058-31, [10]), do not give enough confidence of possible deviations from the requirements of the Rulebook on measuring instruments [3]. The fee for verification of electricity meters which is paid to the Bureau of Metrology of RM 7 Euro for three-phase electricity meters and 4 Euro for single-phase meters), could be used for significant improvement of the equipment and the other preconditions and resources for confident metrological control as well as for insurance of traceability to the national and international standards [11], [12].

The electrical energy consumption in the R. Macedonia, like in other countries, is connected to the life standard and is in constant increase. According to the State Statistical Office in the R. Macedonia 82.6\% (2009) and 83.6\% (2010), out of 8265 837 MWh (2009), i.e. 8677969 MWh (2010), gross domestic consumption of electrical energy is of domestic production, and around $17 \%$ is imported [13,14]. The biggest consumers of electricity in 2010 were the households with a share of $37.3 \%$, the industrial sectors (energy sector plus industry) with $25.3 \%$, and the other sectors with $17.7 \%$ of the gross national electricity consumption. Own consumption (in production, transmission and distribution) of electricity in 2010 was $5 \%$, while distribution losses were $14.7 \%$ of the gross national electricity consumption [14].

All this energy is measured at the level of system interconnections, at the level of large consumers, at the level of industry, at the level of small consumers and households at different voltage levels, different locations, and different types of electricity meters for direct and indirect electrical energy measurements. Currently, in the R. Macedonia approximately 800,000 electricity meters in the households and 7500 meters in the industry are in usage. The electricity meters used in the households of RM were in a large scale three-phase meters, accuracy class 2, produced by ISKRA-Kranj, Slovenia and in smaller scale of domestic production by Video InzeneringOhrid (by licence of Siemens) and Energetika-VDS Strumica (own development). The electricity meters used in the industry are mainly for indirect measurements, accuracy class 1 and 0.5, while the electricity meters at the system interconnections are of accuracy class 0.1 . Roughly, it can be estimated that these meters are used with approximately 30,000 instrument transformers of accuracy class 0.5 .

According to the Law on Metrology it is foreseen first, periodical and, if necessary, extra verification of the electricity meters to be done. The legal period for periodical verification

Table 1. Annual verifications of electricity meters performed by BoM.

\begin{tabular}{llcc}
\hline Year 2007 & Year 2008 & Year 2009 & Year 2010 \\
\hline 101400 & 99800 & 231900 & 180000 \\
\hline
\end{tabular}


of the electricity meters is 10 years, which imposes that approximately 80,000 meters should be verified annually.

According to the data of the Bureau of Metrology [15], in the last years the number of electricity meters verifications performed by the BoM is given in Table 1 .

These figures comprise the number of first verifications performed by the meter producers (foreign producers), as well as the number of periodically verified electricity meters by EVN-Macedonia.

The legal period of verification of instrument transformers is 5 years, so the annual number of verified instrument transformers should be 6000 .

All the meters used for billing the electrical energy must have a type approval and verification. The type approval means compliance of the meter type to the technical standards and the legal regulation. In the procedure of type approval about. 30 different tests, including testing of the electrical and metrological characteristics, isolation tests, mechanical tests as well as some newer tests: software validation, life cycle and confidence, are performed. Practically, it is impossible to test each meter, therefore samples of the newly developed meters are taken, and if all the tests are satisfying, the type approval is issued. The meters identical to the approved ones are considered to comply to the standards. According to the Law, each electricity meter used for billing of electrical energy mus be verified. For verification of the meters and instrument transformers a limited set of tests is required, which is mainly testing of the meter error at different working conditions.

\section{ESTABLISHING OF LEGAL REQUIREMENTS, TRACEABILITY AND CONFIDENCE OF ELECTRICAL POWER MEASUREMENTS}

The current legislation which regulates the measurements of electrical energy in the R. Macedonia is discussed and referred to in Section 2. If this regulation is compared with the regulation for measurement of electrical energy used in the EU countries, it can be noticed that a transposition of the MID directive, [5] is done, but for full coverage of the field of measurements of electrical energy and power, it is necessary to apply the European standards EN 50470-1 [16] and EN 504703 [17] for classes A, B, C (classes A, B and C correspond to accuracy classes 2,1 and 0.5 , respectively). The standards IEC 62052-11 [18], IEC 62053-21 [19] and IEC 62053-22 [20], for classes $2,1,0.5,0.5 \mathrm{~S}$ and $0.2 \mathrm{~S}$ should be applied too.

One of the possible problems in the legal harmonization would be the insurance of indepence, impartiality, integrity and confidence of the bodies performing type testings, calibration and verification. Therefore, changes in the Law on Metrology [1] and in the Rulebook [4] are necessary. The goal of these changes is to enable the activity of independent accredited and authorized bodies for control of electricity meters, independent accredited calibration laboratories and independent services for electricity meters. One of the possible options of organization of the legal metrology for electricity meters is given in Figure 1.

The verification of the electricity meters and the instrument transformers in an authorized inspection body would be realized according to the sequence in Figure 2.

The traceability of the electrical energy measurements to national and international standards could be realized through a three-scale hierarchy chain shown in Figure 3.

For the realization of the traceability chain it is necessary to create a national laboratory which will be equipped with a national primary standard for electrical energy. This laboratory should fulfil the requirements of the standards ISO 17025 [7] as well as to participate at international comparisons with other national laboratories, i.e. to calibrate its standard at national laboratories of other states with standards of a higher accuracy class. This national laboratory and the national standard could be in the frame of the Bureau of Metrology of the R. Macedonia, but also other solutions are possible. The laboratory can be created where staff, equipment and space for such a laboratory already exist.

According to the practice in most of the countries, the calibration laboratories for electricity meters would serve the

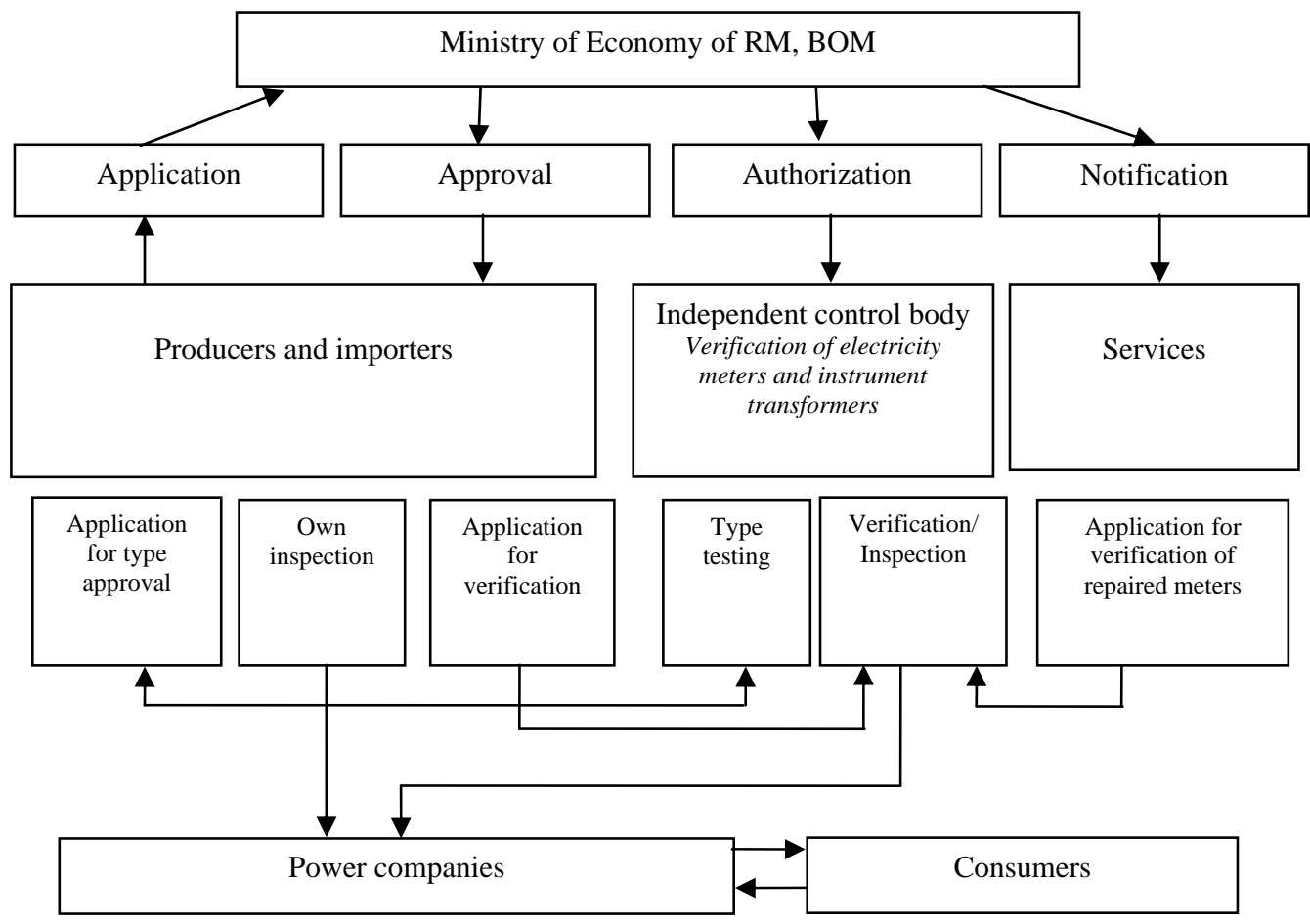

Figure 1. Scheme-proposal on legal metrology of measurements of electrical energy. 


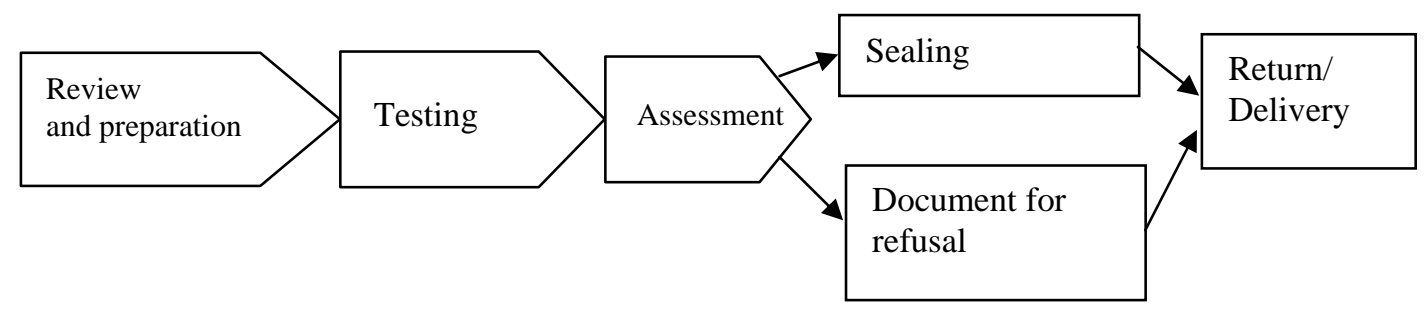

Figure 2. Verification process.

industry and other owners of instruments for electrical energy and power for calibration and type testing, and should be independent laboratories which fulfil the requirements of the standard ISO 17025 [7].

One of the important conditions for insurance of fair trade of electrical energy is the creation of independent and confident control/inspection body for verification of electricity meters. According to the international standard for control bodies ISO 17020 [6], such bodies of Type A should fulfil the following requirements:

1. The inspection body and its staff shall be independent to the parties involved, i.e. shall not be the designer, manufacturer, supplier, installer, and purchaser, owner, user or maintainer of the items which are inspected, nor authorized, representative of any of these parties.

2. The inspection body and its staff shall not be engaged in any activities that may conflict with their independence of judgment and integrity in relation to their inspection activities. In particular they shall not become directly involved in the design, manufacture, supply, installation, use or maintenance of the items inspected or similar competitive items.

3. All interested parties shall have access to the services of the inspection body. There shall not be undue financial or other conditions. The procedures under which the body operates shall be administrated in a non-discriminatory manner.
Beside the organizational, management and documentation requirements, the inspection body must be equipped with competent and responsible staff, which will respect the inspection procedures, criteria and ethics as well as proper equipment which must be calibrated with traceability to the national electrical energy standard. The inspection body should have on disposal proper procedures and protocols of testing and procedures for processing of the results, as well as statistical indicators for the pool of verified meters. For the activities of this inspection body, beside the standard ISO 17020 and the national legislation, there are more international standards and international guides.

\section{CONCLUSIONS}

The current state and the importance of the measurements of electrical energy for billing and other purposes requires quick measures for harmonization and upgrading of the Macedonian system of legal and industrial metrology for electrical energy. It is necessary to establish a national standard of electrical energy and a national laboratory for electrical energy, as well as traceability of the electrical energy measurements to them. It is necessary also to create independent competent calibration and testing laboratories, i.e. independent, impartial and confident inspection bodies for control/verification of electricity meters in compliance to the international standards ISO 17025 and ISO 17020, the standards for electricity meters and the practice in the other countries in Europe and the world. The proposed schemes for practicing the legal metrology and establishing of

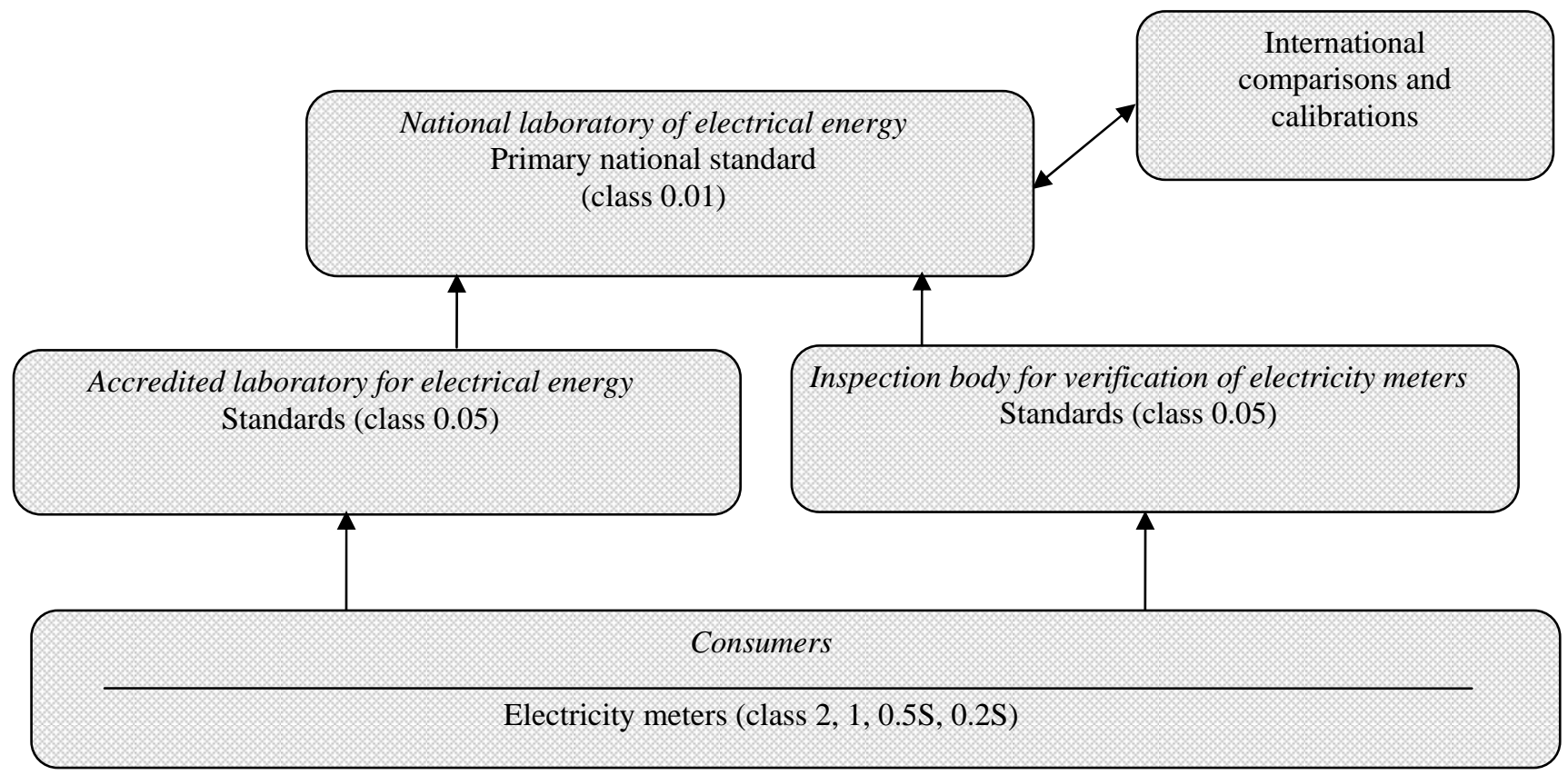

Figure 3. Traceability chain of the electrical energy measurements. 
the traceability chain in the measurements of electrical energy are possible options which should be further elaborated by taking into account all the aspects: legal, current state, staff, technical requirements, as well as the economic aspects.

\section{REFERENCES}

[1] Law on metrology, Official Gazette of R. Macedonia No. 55/02, $84 / 07$ and $120 / 09$.

[2] Rulebook of the definitions, nomenclature and symbols, the scope, application and obligation for usage and writing of the legal measurement units, Official Gazette of R. Macedonia, No. $104 / 2007$

[3] Rulebook on measuring instruments, Official Gazette of $\mathrm{R}$ Macedonia No. $17 / 10$

[4] Rulebook on determination of the categories and types of measuring instruments for which the verification is obligatory, procedures of verification, deadlines of periodical verification and the categories and types of measuring instruments on which an authorization for verification can be obtained, Official Gazette of R. Macedonia", No. 102/2007.

[5] Directive 2004/22/EC on measuring instruments (MID), Official Journal of the European Union, 2004.

[6] EN ISO 17020, General criteria for the operation of various types of bodies performing inspection, Cenelec, Brussels, 2004.

[7] EN ISO/IEC 17025, General requirements for the competence of testing and calibration laboratories, Cenelec, Brussels, 2005.

[8] IEC 62058-11, Electricity metering equipment (AC) acceptance inspection, Part 11: General acceptance inspection methods, International Electrotechnical Commission, Geneve, 2008.

[9] IEC 62058-21, Electricity metering equipment (AC) acceptance inspection - Part 21: Particular requirements for electromechanical meters for active energy (classes 0,5,1 and 2), International Electrotechnical Commission, Geneve, 2008.
[10] IEC 62058-31, Electricity metering equipment (AC) acceptance inspection - Part 31: Particular requirements for static meters for active energy (classes 0,2 S, 0,5 S, 1 and 2), International Electrotechnical Commission, Geneve, 2008.

[11] Decision on the amount and form of payment of the fee for services of the Bureau of Metrology and the authorized legal entity, Official Gazette of R. Macedonia, No. 51/2004, No. 64/2008, No. $121 / 2010$.

[12] Press release No. 0302-864/1 of Bureau of Metrology of R. Macedonia from 1. 03. 2010.

[13] Press release No. 6.1.10.83, State Statistical Office of R. Macedonia from 02.12.2010.

[14] Press release No. 6.1.11.91, State Statistical Office of R. Macedonia from 30.11.2011.

[15] Strategic plan for the development of the bureau of metrology and the metrological infrastructure of R. Macedonia 2010-2012, Bureau of Metrology of R. Macedonia, 2010.

[16] CEN EN 50470-1, Electricity metering equipment (AC) General requirements, tests and test conditions. Metering equipment (class indices A, B and C), Cenelec, Brussels, 2006.

[17] CEN EN 50470-3: Electricity metering equipment (AC) - Part 3: Particular requirements - Static meters for active energy (class indices A, B and C), Cenelec, Brussels, 2006.

[18] IEC 62052-11, Electricity metering equipment (AC) - General requirements, tests and test conditions - Part 11: Metering equipment, International Electrotechnical Commission, Geneve, 2003.

[19] IEC 62053-21, Electricity metering equipment (AC) - Particular requirements - Part 21: Static meters for active energy (classes 1 and 2), International Electrotechnical Commission, Geneve, 2003.

[20] IEC 62053-22, Electricity metering equipment (AC) - Particular requirements - Part 22: Static meters for active energy (classes $0.2 \mathrm{~S}$ and $0.5 \mathrm{~S}$ ), International Electrotechnical Commission, Geneve, 2003. 